\title{
PARA ENCANTAR, É PRECISO ENCANTAR-SE: DANÇAS CIRCULARES NA FORMAÇÃO DE PROFESSORES
}

\author{
LuCiana Esmeralda Ostetto*
}

\begin{abstract}
RESUMO: A dança é uma forma ancestral de magia, invenção dos deuses que a ensinaram aos homens, diz-nos a mitologia hindu. Envolvido no mistério e movimento da dança, o dançarino pode encantar; porém, antes de tudo é preciso que encante a si mesmo. Não seria este também o caminho do professor? Fazer para si para poder fazer ou propor aos educandos, encantar-se para poder encantar; criar para poder seguir com as crianças a aventura da criação; ousar para poder encorajar? Nesta direção, a pergunta que percorre o presente artigo é assim formulada: como contribuir com o processo de encantamento dos professores, como alimentar a sensibilidade, nos percursos da formação universitária? Buscando respostas no processo de pesquisa, identifica-se na experiência com as danças circulares, tradição de diferentes povos, um profícuo caminho pelo qual aquele espaço de encantamento, de inteireza, de educação estética, igualmente, pode ser provocado.
\end{abstract}

Palavras-chave: Educação estética. Danças circulares. Dança na educação. Danças tradicionais. Formação de professores.

TO ENCHANT OTHERS, ENCHANT YOURSELF FIRST: CIRCLE DANCING AND TEACHER TRAINING

ABSTRACT: According to Hindu mythology, dancing is an ancestral form of magic, an invention gods taught to mankind. Wrapped in the mystery and movement of dancing, dancers can enchant others, but they have to enchant themselves first. Should dancing teachers also follow this path? Doing things for themselves to be able to do or propose things to their pupils? Enchanting themselves to

Doutora em Educação e professora do Centro de Ciências da Educação da Universidade Federal de Santa Catarina (UFSC).E-mail: luesmeralda@uol.com.br 
enchant others? Creating to help the children pursue the creative adventure? Daring to encourage? The questions that guide the present paper are: How can one contribute to the process of teachers' enchantment? How can one feed sensibility during continuing teacher education? Looking for answers in the research process, this paper sees in the circle dancing experience, a tradition shared by different peoples, a fruitful way to promote a space for enchantment, wholeness and aesthetic education.

Key words: Esthetic education. Circle dancing. Dancing in education.

Traditional dances. Continuing teacher education.

\section{Perguntas e roteiros de buscas}

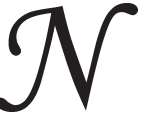

a formação de professores, sobretudo no ofício de professora do curso de Pedagogia, tenho me perguntado: de onde e como vem a sensibilidade? Ela é cultivada, construída, provocada, estimulada, formada? Como vai adiante? É possível educar para a sensibilidade? (Ostetto, 2006b). Os questionamentos formulados transformam-se em guias de investigação, roteiros de buscas que se pautam na importância e na necessidade da arte para a formação de educadores, há tempos defendidas por muitos pesquisadores. Evidenciando a dimensão estética como elemento constitutivo de um projeto educacional-pedagógico comprometido com a formação humana em sua inteireza, pode-se dizer, juntamente com diversos autores (Albano Moreira, 1984; Dias, 1999; Guimarães, Nunes \& Leite, 1999; Nogueira, 2002; Leite \& Ostetto, 2004; Trierweiller, 2008, entre outros), que ampliar repertórios artístico-culturais, provocar o desejo e a curiosidade, instigar a desconfiança do traço acostumado e das certezas absolutas, incentivar a ousadia de desenhar caminhos de busca e experimentação, afirmando autorias, convertem-se em premissas para um trabalho que articule educação e arte de um modo geral e, especialmente, na formação de educadores.

O paradoxo é que, na prática escolar, cujo espaço prescritivo de certa pedagogia ainda reinante reflete a intolerância diante da incerteza e da incompletude da vida, persistem, por exemplo, os desenhos prontos para as crianças pintarem, assim como a prática de escolher os supostos melhores trabalhos para o painel de exposição. É espantoso que hoje, mesmo considerando o avanço das pesquisas e teorias sobre 
Para encantar, é preciso encantar-se: danças circulares na formação de professores

os processos de ensino-aprendizagem, sobre desenvolvimento e culturas infantis, encontremos nas escolas aquelas atitudes com relação à produção das crianças. Sim, o velho desenho pronto (antigamente mimeografado, agora xerografado ou impresso) não caiu em desuso e ainda faz escola! É comum encontrarmos produçôes em série a partir de um modelo, nas quais nem de longe se pode perceber uma criança que pensa e faz. Presenciei o seguinte quadro, não faz muito tempo:

(...) uma sala de pré-escola, repleta de desenhos "mimeografados" e coloridos pelas crianças. Uma decoração com cartazes (estereotipados) de menininhos e menininhas, colados na parede e na lousa. Na mesa da professora, havia lembrancinhas confeccionadas para os pais: podíamos admirar uma série de "camisas" de cartolina, com suas gravatinhas pintadas todas iguais, formando um cartão para homenagear os pais. Na lousa ainda permanecia a frase que certamente todas as crianças copiaram no cartão: pai amo você. (Ostetto, 2006a, p. 107-109)

Dessa maneira, como falar de educação estética na escola, como discutir o gosto? Como pensar que alguém poderá dizer que gosta disso ou daquilo, escolhendo entre isso e aquilo, se na pequenez é submetido a estes disparates? Como pensar em autoria e autenticidade, confinado num campo definido por "siga o modelo"? Eis, claramente estampada, uma forma de se educar esteticamente os meninos e meninas: roubando-lhes linguagens e impondo-lhes uma pobreza de expressão e produção que não alimenta a imaginação de ninguém. Apenas amarra, prende, padroniza. Atrofia.

No espaço massificado, suprimidos os autores, pode-se adivinhar a sombra de um adulto que também não exerce sua autoria. Ao repetir o modelo das famigeradas lembrancinhas para datas comemorativas (no caso, era dia dos pais) e oferecer desenhos prontos para as crianças pintarem, o professor apenas cumpre com uma atividade didática, dissociada de quantos sentidos poderiam ser revelados no fazer das crianças, se lhes fosse oferecida a oportunidade de escolha, validada sua imaginação, acolhidas razão e sensibilidade. Nessa medida, configura-se uma fragmentação da inteireza de ser humano e, assim, de ser professor. Como poderia um sujeito cindido formar sujeitos inteiros? Como imaginar um indivíduo que repete formando indivíduos que criam?

Não é minha intenção avolumar os laudos que denunciam uma escola apartada da vida, que dissocia razão e sensibilidade, cognição e 
afeto, apropriação e criação. Minha reflexão, fertilizada no convívio com as dificuldades e possibilidades da escola (em especial de professores da educação infantil), marcada pela perplexidade e pelo compromisso com a educação pública de qualidade, segue, justamente, com o desafio de compartilhar alternativas que contribuam, em primeiro lugar, para resgatar a pessoa na pessoa do educador, afirmando caminhos de educação estética, marcados pela indissociabilidade de pensamento e sentimento, cabeça e coração, na jornada de formação.

O analista Roberto Gambini (2001) ressalta o fato de que a cultura e a ciência insistem em renegar a dimensão não racional, relacionada ao sentimento, à sensibilidade, à imaginação. Fala, também, da necessidade de se buscar práticas diferenciadas que sejam capazes de ligar o que historicamente vem sendo separado; de se buscar

(...) práticas que formem, além de cidadãos, indivíduos capazes de estabelecer uma conexão mais profunda do que aquela até hoje prevalecente entre a dimensão racional e a não racional, entre pensamento e sentimento, que se lance uma ponte reunindo dois mundos cindidos pela ininterrupta evolução da racionalidade a partir do século XV. Nossa cultura e nossa humanidade, no decorrer da história moderna, acabaram polarizadas: razão e desrazão, consciente e inconsciente, corpo e espírito, normal e anormal... a lista é longa. (Gambini, op. cit., p. 107)

Caberia à educação, em suas diferentes instâncias, trabalhar esses opostos, com vistas à sua integração tanto na cultura como no indivíduo. Teríamos, assim, uma educação que escuta, estimula e valoriza a formação da sensibilidade, do imaginário, da dimensão poética (Gambini, 2001).

$\mathrm{Na}$ trilha anunciada pelo analista, seria fundamental para o educador trabalhar aqueles tantos pares de opostos: encontrar-se com a incerteza, navegar no desconhecido, aprender a olhar, sentir e suportar a incompletude. Desse modo, falar de "repertórios artístico-culturais" dos professores, de educação estética, significa considerar aquele polo insistentemente reprimido na educação: o inconsciente, o não racional. Como pretender o contato com o sensível, com a criação, sem considerar essa dimensão? Como ser autor sem se desviar da consciência prescritiva, do modelo, da verdade estabelecida do reino do seguramente conhecido?

Acontece de nossa tradição estar alicerçada na impossibilidade da união dos contrários. "Ou isto ou aquilo": ser ou não ser, consciente ou 
inconsciente, razão ou emoção, pensamento ou sentimento, bem ou mal, certo ou errado? Todavia, diante da complexidade da vida contemporânea, mais do que nunca é prudente afirmar, tal como já indicara Jung (2001, p. 23), outras formas de compreensão em que o coração não se oculte "sob o manto da chamada compreensão científica", tipicamente ocidental. Além de (e mais do que) explicar e conceituar, seriam necessários roteiros de aprendizagem que provocassem deslocamentos, que convidassem àquele em formação a ousar se embrenhar pelas veredas do desconhecido, descortinando outras paisagens e histórias, aproximando-se e dialogando com universos culturais distintos dos seus, acolhendo a diferença.

Nesse ponto, encontro-me com a dança e, nela, com o mito do dançarino cósmico, tentando amplificar a discussão proposta, aprendendo que, para encantar, é preciso encantar-se. Refiro-me à tradição hindu, na qual Shiva Nataraja é o senhor da dança, aquele que personifica e manifesta a força e os poderes de dissolução, evolução e preservação do universo. É o dançarino cósmico que, no seu girar incessante, faz mover a energia eterna: criação-expansão, preservação-duração, destruição-renovação (Zimmer, 1989).

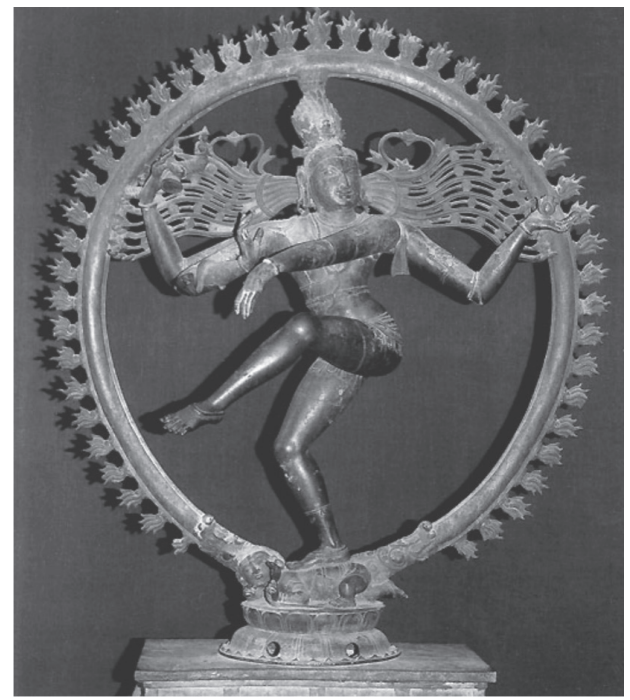


$\mathrm{Na}$ conhecida imagem, Shiva Nataraja segura na mão direita superior um tambor, feito ampulheta, marcando o ritmo, a energia do som criador. Traz em sua mão esquerda superior uma língua de fogo, o elemento da destruição e símbolo da transformação. Observamos, no equilíbrio entre as mãos, o equilíbrio criação-destruição na dança cósmica. A segunda mão direita eleva-se no gesto de paz e proteção: "não temas"; enquanto a outra mão esquerda, em sinal de graça, aponta para baixo, para o pé esquerdo erguido, símbolo de liberação. A divindade pisa sobre o demônio caído, símbolo da ignorância e cegueira da vida humana. Um anel de chamas e de luz emerge do deus e o rodeia: "a energia da sabedoria, a luz transcendental do conhecimento da verdade, cuja dança emana da personificação do todo" (Zimmer, 1989, p. 124).

A coreografia incessantemente executada é o redemoinho do tempo, o ritmo cíclico: vida, morte e renascimento. $\mathrm{O}$ universo é o movimento. Da tradição hindu aprendemos que a dança é uma forma ancestral de magia. Através dela a personalidade do dançarino se transforma, expande-se, chega à vivência do divino. Eis um porém: "para exercer a magia, para lançar encantamento sobre outrem, é preciso que o indivíduo em primeiro lugar encante a si mesmo" (idem, ibid., p. 123).

$\mathrm{O}$ mito que envolve a magia da dança faz-me pensar no educador e na necessidade de encantar-se para poder encantar; criar para poder seguir com as crianças a aventura da criação; ver beleza, viver a beleza para poder espalhar beleza; abrir-se à escuta e ao olhar do inusitado e misterioso, acolhendo múltiplos sentidos no mundo, para poder ser sensível e acolher diferentes significados e sentidos construídos pelas crianças no cotidiano educativo; ousar para poder encorajar.

Como contribuir com o processo de encantamento dos professores, nos percursos da formação universitária? A pesquisa e a experiência com uma específica e particular proposta de dança, as danças circulares dos povos, indicaram que podemos provocar, a exemplo do que nos ensina a tradição hindu (com seus mitos e infinidade de símbolos dela decorrentes), a busca daquele espaço de encantamento, de experiência estética, espaço-tempo de reencontro com a dimensão poética do ser. Uma busca essencial para o educador, uma vez que, no seu ofício de ensinar e aprender, transita pelos territórios da imaginação, da criação, da transformação. 
Entrar na roda, mãos dadas no instante: todos os sentidos

$\mathrm{Na}$ história de sua existência, os homens dançaram todos os momentos importantes da vida: da guerra à paz, do casamento aos funerais, da plantação à colheita, os ciclos observados na natureza, a mudança das estaçôes (Garaudy, 1980). Por meio da dança, o homem identificava-se com os ritmos da natureza, reconhecia e imitava os movimentos e as forças nela presentes.

$\mathrm{Na}$ dança a comunidade se reunia e marcava seu pertencimento, vivendo e partilhando valores e crenças. Dançar era celebração, participação, encontro e reafirmação dos ciclos da vida, na tensão entre os mistérios humano e divino. Nesse sentido, a dança concedia "uma resposta tanto à chamada da vida, como à da morte, afirmando o misterioso como uma das dimensões da existência" (Wosien, 1997, p. 16).

As danças circulares sagradas, tal como hoje as conhecemos, trazem em suas raízes esse passado longínquo da dança dos povos. Reencontram e recuperam a dança como comunhão e transcendência, uma prática comunitária e gregária. Como no passado, qualquer pessoa pode participar dessa dança, basta entrar na roda, dar as mãos e se abrir para o encontro além da palavra.

Como o próprio nome indica, as danças circulares sagradas são práticas de dança desenvolvidas em círculo, envolvendo simbologias, tradição e cultura de diferentes povos. $\mathrm{Na}$ roda, de mãos dadas, voltada para um centro comum, ao ritmo de suas músicas, nos passos e nos gestos desenhados no movimento coletivo, as marcas de tradiçōes diversas são dançadas e acolhidas, são vivificadas no círculo.

Hoje seria quase impossível relacionar todas as origens das danças, pois os mais diversos povos e tradições religiosas são honrados no movimento, assim como o repertório musical perde-se de qualquer tentativa de ordenação, tão variado que é. São, por exemplo, danças da Grécia, Albânia, Romênia, Iugoslávia, Bulgária, Hungria, Macedônia, Israel, Rússia, Escócia, Irlanda, Letônia, Estônia, Índia, Brasil, povos da América do Sul.

Ao dançar, geralmente de mãos dadas, o grupo descreve formas variadas no espaço. A principal e mais comum é a formação em círculo, que pode abrir-se ou fechar-se, desenhando linhas, espirais, meandros na sua movimentação. As danças de pares são também bastante comuns e 
lembram diretamente as tradicionais danças de roda festivas. A direção da roda igualmente varia de sentido. O significado da direção empreendida em cada dança depende da tradição em que se insere, ou do simbolismo impresso pelo coreógrafo. De modo geral, compreende-se que o sentido horário, lado esquerdo, é a direção do passado, e o sentido anti-horário, lado direito, do futuro. Conforme Wosien (2000), no sentido horário estaria o fluxo das lembranças, e, no contrário, o fluxo do conhecimento e da iluminação.

Também a posição das mãos e dos braços carrega simbologias distintas. Antes de qualquer movimento, no ato de juntar as mãos entre si, os dançarinos formam um campo de energia que circula no grupo, pela posição das mãos: uma com a palma para baixo - simbolizando o dar, e outra para cima - simbolizando o receber. "Quando os dançarinos se ordenam num círculo, de acordo com a tradição, eles se dão as mãos. A mão direita torna-se a que recebe e a esquerda a que dá" (idem, ibid., p. 29).

Braços estendidos para baixo (dizemos em "V", pois é o desenho que se forma na junção dos braços de um e outro dançarino no círculo) significam a conexão com a terra; braços dobrados na altura do coração (dizemos em "W") representam a conexão na roda, no aqui e agora; braços elevados para cima, em direção aos céus, conexão com o infinito, a força superior. Há também a posição em que os braços se cruzam em espiral, simbolizando "força, unidade e eternidade" (Barton, 1995, p. 7).

Preparar o espaço, estabelecer um centro em torno do qual a roda se move, também faz parte do ritual das danças sagradas. Tal como o círculo, tudo converge para o centro. É nele que está simbolizada a fonte, a criação, a luz, o ponto comum que une a todos.

A experiência de dançar no círculo é particular e polissêmica. Nesse sentido, um dos aspectos importantes de se ressaltar é a entrega do participante. Basta ir, sem receio de fazer errado; deixar-se ir ao encontro do incerto e aventureiro dos passos na roda. Mas é necessário o desejo, a disposição para o reconhecimento das polaridades da vida, para poder respeitar o ritmo interno, ser fiel ao seu tempo. Ao ficar frente a seus limites, ao admitir o espaço do erro, fica como que franqueada uma passagem para cada qual olhar para dentro, apropriarse da expressão e coragem interditada ou reprimida, ouvir a própria voz 
e acreditar no seu eco e direção (que podem até destoar do mundo em geral, mas em algum lugar ressoa...).

Ao dançar o passado, entramos em contato com símbolos e rituais de diferentes culturas e, como diz Bernhard Wosien (2000), o mestre que inspirou o movimento das danças circulares sagradas: na dança o mundo é novamente circulado e passado de mão em mão. Esse é o convite!

Danças circulares, pesquisa e formação: outras linguagens, educação estética

Minha experiência e encantamento com a prática das danças sagradas dos povos conduziram-me a entrar na roda com educadoras, para dançar e pesquisar. Desenvolvi minha pesquisa de doutorado (Ostetto, 2006a) a partir de "encontros para dançar", com duas turmas de alunas do curso de Pedagogia e com educadores que atuavam na educação básica.

Considerando que na roda, de mãos dadas e voltados para um centro comum, outras formas e dimensóes do conhecer poderiam ser acionadas, o curso da investigação propôs aos educadores participantes a experiência de dançar/fazer para si mesmo, abrindo-se à escuta de si mesmo. É preciso assinalar, portanto, que a proposta não foi dar aulas de dança, ensinar coreografias como repertórios de fazer, para que repassassem aos seus alunos, mas criar um espaço no qual "a pessoa na pessoa do educador” pudesse ser reconhecida e mobilizada.

As danças circulares estão ligadas àquele conjunto de práticas e saberes que foram negados e relegados pela ciência clássica, no seu afã de tudo classificar e controlar. Como conteúdo esquecido pelo homem moderno, condenado ao império da razão, pode ser um dos caminhos para restabelecer o contato com dimensões perdidas no mundo do "eu como consciência”, fundado com a modernidade.

Ao propor as danças circulares aos professores, propus outra forma de linguagem, diversa do habitual dentro do espaço curricular. Uma linguagem através da qual a consciência pode ser deslocada, fugir do controle, revelando o não dito. $\mathrm{Na}$ forma ritualística da linguagem da dança no círculo - as mãos dadas, os gestos repetidos acompanhando a música, a simbologia vivenciada na composição da coreografia - a 
atenção pode ser desarmada. A dança circular, como meditação em movimento, convidando ao silêncio, possibilita esvaziar o que está saturado. Nos passos da roda de dança, no círculo que move e remove tempos e experiências, configura-se um ritual que é prenúncio da abertura para acolher o mistério, o vir a ser, que pede passagem para cada um dos participantes.

A pesquisa revelou e afirmou as danças circulares sagradas como oportunidades de imaginação ativa (Jung, 1991b), campo aberto para a aproximação dos opostos, um caminho propício para configurar o reino intermediário, onde o poder da imaginação é que conta e, a partir da sua atuação, o mundo interno é alargado.

A dissociação das funções psicológicas do homem e, principalmente, o afastamento do contato com conteúdos do inconsciente, características da sociedade moderna, estão na base da crítica que o psicólogo suíço Carl Gustav Jung dirige a uma cultura altamente desenvolvida, responsável pela uniformização das forças individuais, na unilateralidade do pensamento. Deste ponto, buscará e afirmará o espaço intermediário, no qual a personalidade consciente e o inconsciente se relacionam, sem se negarem mutuamente. É neste lugar do "entre", com a marca essencial da produção de símbolos, que vemos anunciada a possibilidade da criação. É neste lugar, o terceiro reino, que se afirma o poético, o metafórico; que não está nem lá nem cá, nem na consciência nem no inconsciente (Maroni, 1998). Um lugar tecido com o que Jung (1991a, p. 63) chamou de "fantasia ativa":

A realidade viva não é dada exclusivamente pelo produto do comportamento real e objetivo das coisas, nem pela fórmula ideal, mas pela combinação de ambos no processo psicológico vivo, pelo esse in anima. Somente através da atividade vital e específica da psique alcança a impressão sensível aquela intensidade, e a ideia, aquela força eficaz que são os dois componentes indispensáveis da realidade viva. (...) A única expressão que me ocorre para designar esta atividade é fantasia.

A fantasia é a atividade específica da psique, uma atividade sobretudo criativa, que conduz o homem a um processo ilimitado de simbolização e, por conseguinte, de expansão da consciência e de novas possibilidades de pensar e fazer o mundo. A fantasia, nos diz Jung (op. cit., p. 64), “é a mãe de todas as possibilidades, onde o mundo interior e exterior formam uma unidade viva, como todos os opostos 
Para encantar, é preciso encantar-se: danças circulares na formação de professores

psicológicos”. A fantasia revela-se nos sonhos, no devaneio, na imaginação. Entretanto, há que distinguir a fantasia ativa, em que tanto um processo inconsciente quanto disposições da atitude consciente entram em jogo para "assumir os indícios ou fragmentos de relações inconscientes e relativamente pouco acentuadas e, por meio de associação de elementos paralelos, apresentá-los numa forma visual plena” (idem, p. 407). O importante a ser destacado aqui é a participação positiva da consciência, diferente do que acontece no sonho, considerado fantasia passiva.

A fantasia ativa, como processo que permite aproximar consciência e inconsciente, produzindo algo novo, tem o mesmo estatuto que outro termo cunhado por Jung (1984, p. 74): função transcendente, assim chamada "porque torna possivel organicamente a passagem de uma atitude para outra, sem perda do inconsciente". A dinâmica envolvida no processo foi assim apresentada:

A confrontação entre as posições contrárias gera uma tensão carregada de energia que produz algo vivo, um terceiro elemento (...) um deslocamento a partir da suspensão entre os opostos e que leva a um novo nível de ser, a uma nova situação. A função transcendente aparece como uma das propriedades características dos opostos aproximados. Enquanto esses são mantidos afastados um do outro - evidentemente para se evitar conflito - eles não funcionam e continuam inertes. (p. 90)

Se, através da função transcendente dos opostos, surge uma modificação do ponto de vista, uma vez confrontados fatores conscientes (racionais) com inconscientes (irracionais), Jung acentua: "Mas uma mudança somente é possível se a 'outra coisa' tiver sido permitida, ao menos até que se tenha conscientemente tomado conhecimento dela” (1988, p. 192).

Eis a possibilidade anunciada da unificação dos opostos, a interrelação de polaridades, marcando a modificação de pontos de vista: a emergência do símbolo. Simbolizar é descobrir outros sentidos, ir além do conhecido, atravessar fronteiras; é fazer ligações, unir fragmentos, expandir a personalidade. Há nesta dinâmica um convite a um curioso escutar e ver as coisas de modo diferente. Não de explicá-las, ou mesmo compreendê-las, mas de não negar o desconhecido e, talvez, surpreender-se com o que aparece. Aí está o germe da criação.

A vida, contínua transformação, justifica-se pela busca do mistério. E, neste caminho, relembrando as funções psíquicas delineadas por 
Jung, é a intuição que nos conduz à expansão, à criação, na medida em que nos impele ao encontro de territórios desconhecidos. Ao tratar dos aspectos da psicologia da obra de arte e de seu criador, Jung (1991b, p. 83) atribui um valor essencial à intuição como guia, como aquela que "conduz-nos a áreas desconhecidas e ocultas, a coisas que, por sua natureza, são secretas". Abrir-se à intuição é como livrar-se da proteção que "o escudo da ciência e da razão" oferece ao homem, fixando-o na temporalidade do presente. É dar passagem ao pensamento-fantasia, uma forma de pensar que coexiste com o pensamento dirigido (Jung, 1999).

Através do pensamento dirigido, só transitamos por caminhos já trilhados, recompomos o já conhecido. O novo emerge do pensamento-fantasia, nascido no "entre", quando experimentamos um estado de atenção flutuante, vale dizer, relaxado, da consciência: "Pelo pensamento-fantasia se faz a ligação do pensamento dirigido com as 'camadas' mais antigas do espírito humano, que há muito se encontram abaixo do limiar do consciente" (idem, ibid., p. 25).

Se o pensamento dirigido nomeia, classifica, instala, põe ordem, aloja o que não tem lugar, o pensamento-fantasia, ao contrário, diferencia, cria, toca o indizível, provoca o movimento na tensão dos contrários, desaloja. Se nos colocamos em posição de escuta, receptivos aos mistérios do mundo, àquelas porçôes não aprisionadas nos limites do conhecidamente provado e comprovado no campo do possível, seguimos às margens do impossível, atravessamos uma fronteira e então outra e outra mais.

Apresentar e admitir a discussão posta por Jung é, sobremaneira, importante para ampliar a análise do trabalho realizado com as danças circulares sagradas na interface de uma proposta de formação de professores. Como falar de criação e reinvenção do cotidiano educativo e da vida, reivindicando a poesia nossa de cada dia, sem romper com a unilateralidade posta, sem considerar intuição e sentimento como funções psíquicas essenciais? Seguimos, assim, de passagem em passagem, travessia após travessia, braços dados com a imaginação, que nos permite conviver com a inquietude, experimentando o "espaço intermediário", reino da criação.

A dança no círculo é um momento especial, um instante profundo de recriação da pessoa, na coragem de encarar a roda e a aventura que cada dança poderá ativar. Aceitar o convite da dança é, sem 
dúvida, uma passagem, a entrada por um portal que conduz a pessoa para si mesma, para territórios distanciados, mas extremamente próximos de si. Cada um poderá atravessar ou não esse portal, mas, atravessado, mergulha-se num reino de fantasia, de imaginação. Como não pensar na simbologia evocada em cada dança? Como não pensar nos povos, nas tradições trazidas ao presente? A dança tira-nos do lugar, mostrando outros lugares - em nós e no mundo. A coragem e a disposição de entrar na roda, aceitando os limites do corpo e, muitas vezes, a estranheza dos passos e música, são pontos de partida fecundos para o desprendimento e abertura da pessoa para outros universos.

Nesse sentido, as danças circulares sagradas não ensinam um programa, uma técnica, um modo de fazer com as crianças. Ensinam possibilidades de encontro com conteúdos que falam a cada dançarino em particular, trazem e fazem sentidos articulados ao viver de cada um. Essa é a essencialidade das danças circulares: sinalizar e abrir passagem para acessar conteúdos negados, reprimidos ou desqualificados no mundo da racionalidade científica. É, enfim, a possibilidade de encontro com conteúdos inconscientes, ativando outras funções da consciência, além do pensamento.

Mais do que a qualquer resultado objetivo, de conhecimento ou comportamento, a dança circular conduz às fronteiras do desconhecido. Ela não define, não explica. Apenas abre. E, por ela se abrir a significados e sentidos na experiência, para territórios conscientes e inconscientes, convida ao acolhimento do não conhecido, não pensado, não vivido. Dançando vamos, justamente, "lá" onde não entendemos. Vivemos o "entre".

Por mais temeroso que seja habitar paisagens dantes não reconhecidas, por mais angustiante que seja dar os primeiros passos rumo ao "não sei onde vai dar a estrada", enfim, por mais espantoso que seja dar as mãos na roda e movimentar-se com outros, o círculo dançante apresenta-se como uma paisagem viva e repleta de possibilidades. $\mathrm{O}$ reino das certezas (no nosso caso, das prescrições pedagógicas), com explicaçôes demasiadas, negando as dúvidas e o não saber, oferece uma pretensa segurança; porém, também impede a emergência do novo. Bloqueia a travessia, interdita a criação, deixa a alma no deserto.

"O deserto é uma metáfora da árida paisagem psicológica, onde a criatividade e a geratividade estão ausentes, onde nada floresce e a 
vida é sem sentido e emocionalmente monótona” (Bolen, 1996, p. 155). As danças circulares podem se apresentar como ligação, como espaço de irrigação dos jardins da alma (o "entre"), contra a desertificação. $\mathrm{Na}$ quietude dos gestos na roda, no acalento da música que ecoa, o espaço intermediário é tocado. Alimentado e revigorado no ritual e no simbolismo evocados no círculo dançante, ganha força para se manifestar. Sua linguagem, que é poética, pode então ser despertada.

Dançar no círculo. Experimentar outras linguagens, educação do sensível. Colocar-se em atitude receptiva, a ponto de poder ouvir o “murmúrio das vozes internas" (Hillman, 1984, p. 151) em seu particular idioma: fantasia, metáfora, analogia, poesia. Assim, ensaiaremos novos passos e, talvez, possamos ir quebrando a rigidez das verdades pedagógicas, experimentando a mobilidade de pensamento, negando o aprisionamento do fazer educativo no discurso do único. No diálogo com a arte, anuncia-se uma possibilidade de afirmar a multiplicidade e a beleza da vida, reivindicando essa mesma beleza para o cotidiano escolar.

Recebido em julho de 2008 e aprovado em março de 2010.

\section{Referências}

ALBANO MOREIRA, A.A. O espaço do desenho: a educação do educador. São Paulo: Loyola, 1984.

BARTON, A. Espírito da dança. São Paulo: triom, 1995. v. 1-2.

BOLEN, J.S. O caminho de Avalon: os mistérios femininos e a busca do Santo Graal. Rio de Janeiro: Record; Rosa dos Tempos, 1996.

DIAS, K.S. Formação estética: em busca do olhar sensível. In: KRAMER, S. et al. (Org.). Infância e educação infantil. Campinas: Papirus, 1999. p. $175-201$.

GAMBINI, R. Sonhos na escola. In: Scoz, B. (Org.). (Por) uma educação com alma: a objetividade e a subjetividade nos processos ensino/aprendizagem. 2. ed. Petrópolis: Vozes, 2001. p. 103-157.

GARAUDY, R. Dançar a vida. Rio de Janeiro: Nova Fronteira, 1980. 
Para encantar, é preciso encantar-se: danças circulares na formação de professores

GUIMARÃES, D.; NUNES, M.F.; LEITE, M.I. História, cultura e expressão: fundamentos na formação do professor. In: KRAMER, S. et al. (Org.). Infância e educação infantil. Campinas: Papirus, 1999. p. 159-174.

HILlmAN, J. O mito da análise. Rio de Janeiro: Paz \& Terra, 1984.

JUNG, C.G. A dinâmica do inconsciente. Petrópolis: Vozes, 1984.

JUNG, C.G. Mysterium coniunctionis. 2. ed. Petrópolis: Vozes, 1988.

JUNG, C.G. Tipos psicológicos. Petrópolis: Vozes, 1991a.

JUNG, C.G. O espirito na arte e na ciência. 3. ed. Petrópolis: Vozes, $1991 \mathrm{~b}$.

JUNG, C.G. Símbolos da transformação. 4. ed. Petrópolis: Vozes, 1999.

JUNG, C.G. Comentário europeu de C. G. Jung. In: JunG, C.G.; Wilhelm, R. O segredo da flor de ouro. 11. ed. Petrópolis: Vozes, 2001. p. 21-80.

LEITE, M.I.; OSTETTO, L.E. Formação de professores: o convite da arte. In: Ostetto, L.E.; Leite, M.I. Arte, infância e formação de professores: autoria e transgressão. Campinas: Papirus, 2004. p. 11-24.

MARONI, A. Jung: o poeta da alma. Porto Alegre: Summus, 1998.

NOGUEIRA, M.A. A formação cultural de professores ou a arte da fuga. 2002. Tese (Doutorado em Educação) - Faculdade de Educação, Universidade de São Paulo, São Paulo.

OSTETTO, L.E. Educadores na roda da dança: formação-transformação. 2006a. Tese (Doutorado em Educação) - Programa de Pós-Graduação em Educação, Universidade Estadual de Campinas, Campinas.

OSTETTO, L.E. A arte no itinerário da formação de professores: acender coisas por dentro. Reflexão e Ação, Santa Cruz do Sul, v. 14, n. 1, p. 29-43, jan./jun. 2006b.

TRIERWEILLER, P.C. A formação artístico-cultural do professor de educação infantil: experiências, trajetórias e significações. 2008. Dissertação (Mestrado em Educação) - Programa de Pós-Graduação em Educação, Universidade Federal de Santa Catarina, Florianópolis. 
WOSIEN, B. Dança: um caminho para a totalidade. São Paulo: TRIOM, 2000.

WOSIEN, M.G. Danças sagradas: o encontro com os deuses. Madrid: Edições del Prado, 1997.

ZIMMER, H.R. Mitos e simbolos na arte e civilização da Índia. São Paulo: Palas Athena, 1989. 